\title{
RESEÑA DE LA OBRA CÉSAR NICOLÁS PENSON Y SU PASIÓN POR LAS LETRAS: ANTOLOGÍA Recopilación, introducción y notas de Evelyn Marte Rodríguez
}

\section{Por Carlos Enrique Cabrera}

Profesor del Instituto Tecnológico de Santo Domingo (INTEC), República Dominicana. carlos.cabrera@intec.edu.do

Todo nuevo libro que sale a la luz pública debe ser recibido con júbilo y agradecimiento extremos por los ciudadanos que aman la cultura y el saber, máxime si se trata de uno como este que hoy tengo el honor de reseñar el texto César Nicolás Penson y su pasión por las letras: Antología; recopilación, introducción y notas de Evelyn Marte Rodríguez, publicado recientemente por el Instituto Tecnológico de Santo Domingo. El libro es, a mi entender, hace una aportación sustancial al conocimiento de una de las figuras más relevantes de las letras y la cultura dominicanas del siglo XIX, cuya producción -salvo por Cosas añejas: Tradiciones y episodios de Santo Domingo (1891), y por Costumbres antiguas y modernas de Santo Domingo, publicada por primera vez en la década de los cincuenta y, posteriormente, en 1978, por la Fundación García Arévalo- había permanecido hasta ahora dispersa en diarios y revistas de diversa naturaleza $y$, por tanto, literalmente sepultada en el más lamentable olvido.

César Nicolás Penson -figura antologada in extenso en la presente obra- ejerció como abogado, juez, periodista y maestro, formando parte del personal
En esta tierra de tan pocos estimulos para el escritor, merece siempre bien el que, luchando y luchando, hace algo por nuestra incipiente literatura.

$$
\begin{array}{r}
\text { El Lápiz, No 21, Santo Domingo, } \\
\text { diciembre } 6 \text { de } 1891
\end{array}
$$

docente del Instituto de Señoritas con Salomé Ureña de Henríquez y del Colegio San Luis Gonzaga, junto a Rafael Justino Castillo, Luis Desangles y Federico Henríquez y Carvajal, entre otros. No obstante, como señala Manuel de Jesús Mañón Arredondo (1977), "fue en lo literario donde se destacó por su vigor narrativo, su prosa bien clara y elegante y por la originalidad de los temas que abordó”. (p. 481)

Autor adscrito al romanticismo latinoamericano; como tal, participará de los rasgos característicos de este vigoroso movimiento literario decimonónico: veneración por el pasado y la historia, acendrado patriotismo, visión imaginativa y fantasiosa de la literatura y creencia en la perfectibilidad del ser humano y de la sociedad en su conjunto, mostrando una férrea fe en la civilización y el progreso indefinidos, impulsados por la ciencia, la educación y el arte.

Nació nuestro acucioso autor en la antigua ciudad de Santo Domingo, el 22 de enero de 1855; murió a causa de una hemorragia cerebral, el 29 de octubre de 1901, en la misma ciudad, cuando apenas contaba 46 años de edad. Sin embargo, en ese corto 
período su pasión por el saber, por el conocimiento y por las letras -y reitero: su fe en la perfectibilidad del ser humano y de la sociedad- lo lleva a incursionar en diferentes géneros con desigual éxito, pero siempre con gran honestidad, entrega y oficio.

Tendremos así el César Nicolás Penson periodista que pergeña editoriales, artículos de opinión y crónicas, que crea y funda periódicos y revistas (fundó el primer diario de la República Dominicana, El Telegrama, en 1882); el ensayista (primer ensayista dominicano); el cuentista; el poeta de temas patrióticos, románticos y de tendencia social; el escritor costumbrista que rescata las leyendas y estampas: "nuestro escritor que más se ocupó en recoger a la posteridad las tradiciones folklóricas de Santo Domingo" (Mañón Arredondo, 1978); el precursor de los estudios literarios y filológicos en el país; el crítico literario; el biógrafo de relevantes personalidades de la vida nacional (Antonio del Monte y Tejada, Jacinto de la Concha, Abelardo Rodríguez Urdaneta, etc.) y el traductor de versos y prosas del francés, portugués e italiano. La oda "El Cinco de Mayo", del célebre poeta y novelista milanés Alessandro Manzoni (recogida en la presente publicación) fue valorada por Menéndez y Pelayo como una de las mejores versiones.

César Nicolás Penson fue además francmasón (su nombre figura como Venerable Maestro en la lista de la Logia Nuevo Mundo Núm. 5, Inc. en 1884); militó de forma activa en el Partido Azul, liderado por el general Gregorio Luperón, que desde 1857 defendió los principios liberales; sostuvo amplias relaciones epistolares con relevantes figuras de la vida intelectual dominicana y del exterior, tales como Rufino José Cuervo, Rafael Merchán, Juan León Mera, Marcelino Menéndez y Pelayo, Gastón Fernando Deligne, Pedro Tomás Garrido, Luis Cambiaso, José Gabriel García, José Joaquín Pérez y Manuel de Jesús de Peña y Reinoso; varias de estas cartas se reproducen en la antología. Participó con gran entrega y entusiasmo del asociacionismo cívico y cultural de la época. Al respecto, en el prólogo de su edición de Cosas añejas, Rita Tejada (2015), nos dice:
Penson mantenía una agenda muy activa en la sociedad dominicana de la época, participando en muchas de sus agrupaciones de carácter cívico y literario: «Sociedad Amigos del Adelanto» (miembro y redactor de su periódico), Sociedad Amigos del País (miembro, secretario general y presidente en diversos momentos de su existencia, organizador de sus veladas culturales; director de las publicaciones Historia de Santo Domingo de Antonio del Monte y Tejada y Poesías de Manuel Rodríguez Objío, patrocinadas por esta sociedad); y Unión Iberoamericana (en calidad de miembro de la comisión de historia, geografía y literatura). (pp. 12-13)

Tal como señaló Emilio Rodríguez Demorizi (1882/1940): "Nadie ha trabajado en el país, en el campo de las letras y en tan breve existencia, como este gladiador de la cultura. [...]”. Cierto. César Nicolás Penson luchó animosamente en condiciones sumamente adversas; sobre esto, señalaba Eugenio Polanco Velázquez, en 1891, en su crítica a Cosas Añejas, la falta de estímulo y los "obstáculos casi insuperables" a los que se enfrentaban los literatos de la América Latina. Luchó con gran dedicación y entrega para, como precisa Evelyn Marte Rodríguez (2017) en la introducción a su antología "establecer la simiente del patrimonio cultural dominicano y por lograr que América tuviera literatura propia”. (p. 7) Gustavo Penson (1940) refrenda este juicio cuando afirma del autor: "Su ayuda a la Historia Patria y a la Literatura del Nuevo Mundo débese a que fue siempre empeño suyo que "la América tenga literatura propia".

La antología de textos y documentos de César Nicolás Penson que Evelyn Marte Rodríguez pone generosamente en nuestras manos, obra voluminosa de 542 páginas, está estructurada en siete capítulos, a los que se suma una introducción, una amplia bibliografía (bibliografía, bibliografía complementaria y fuentes consultadas), cuatro apéndices y un útil índice onomástico, además de numerosas notas al pie de página de variada extensión, siempre atinadas y pertinentes. 
Los siete capítulos de la antología recogen los siguientes materiales de y sobre César Nicolás Penson: "Ensayos filosóficos y críticos" (Cap. I); "Editoriales-artículos de opinión-crónicas" (Cap. II); "Cuentos" (Cap.III); "Poemas" (Cap. IV); "Epistolario y biografías" (Cap. V); "Trabajos filológicos y literarios y documentos relativos o relacionados con las asociaciones culturales y recreativas a las que perteneció el autor" (Cap. VI); "Primera edición de la obra Cosas añejas y críticas literarias" (Cap. VII). En los apéndices (I al IV) se ofrece al lector y al estudioso valiosos materiales documentales relacionados con el autor: "Rasgos biográficos de César Nicolás Penson”, por Gustavo Penson; "César Nicolás Penson: documentos, apuntes y gráficas sobre su historia personal"; "Genealogía de la familia Penson Matos"; "Cronología de César Nicolás Penson Matos".

Es de rigor consignar aquí las numerosas ilustraciones y reproducciones facsimilares que complementan la obra y que enriquecen, sin duda, su valor documental: portadas de diarios y revistas de la época, cartas y obras - portada original de Cosas añejas (1891) y portada manuscrita de Costumbres antiguas y modernas de Santo Domingo (1894)-; cuadros y grabados; fotografías del mismo autor y de figuras relevantes de la época: Eugenio María de Hostos junto a un grupo de alumnos del Instituto Profesional de Santo Domingo de Guzmán; el Consejo de Dirección del Instituto de Señoritas, entre otras.

La labor de Evelyn Marte Rodríguez es loable y meritoria en grado sumo. Es grande el esfuerzo que supone la recopilación documental y la localización de las fuentes de obligada consulta; la transcripción paciente de los numerosos documentos (con la más estricta fidelidad a los originales); y, posteriormente, su organización, según un esquema racional que haga inteligible y fácilmente manejable el conjunto; además, se procedió, como imprescindible tarea complementaria, a dotarlo de los paratextos de búsqueda, aclaración y referencia. En la introducción a la obra, Evelyn Marte destaca su esfuerzo con objetividad y sin falsa modestia: "Una compleja y tediosa tarea propia de un equipo de personas, pero que poco a poco pude lograr con perseverancia y vocación de servicio".

Lo digo ahora con palabras que ya sonaron en el siglo al que la antología nos hace viajar y de cuya situación general -cultural, social, educativa y política- nos da una clara visión. Son palabras sin firma, recogidas en la página 2 de El Teléfono, del 27 de febrero de 1891, bajo la columna "Sueltos», con el encabezamiento "Publicaciones", referidas a Cosas añejas, pero que hoy quiero hacer igualmente válidas para Evelyn Marte Rodríguez y su obra: "Recomendamos este libro á nuestros conciudadanos; merece ayuda eficaz quien en noble empeńo se esfuerza y trabaja en provecho de las letras nacionales".

Solo me resta alentar a Evelyn Marte Rodríguez a que, siguiendo los pasos de César Nicolás Penson y su luminoso e inspirador ejemplo, continúe su labor tesonera a favor de las letras dominicanas; así, más temprano que tarde, en el menor lapso de tiempo posible, nos regale un segundo volumen que vendría a completar la notable aportación de esta valiosa y necesaria obra que hoy reseñamos con entusiasmo, pues como la misma compiladora nos revela en su introducción: "existen otros interesantes trabajos de la autoría de don César Nicolás Penson, no incluidos en la presente edición por razones de espacio, pero que bien pudieran llenar las páginas de otra posible segunda parte similar a la presente".

En la revista El Lápiz, del 21 de abril de 1891, se lee:

Háse repartido últimamente, nos dicen, la tercera entrega de "Cosas Añejas», del castizo escritor D. César Nicolás Penson. Penson es el único de nuestros escritores que no desmaya ante el indiferentismo, ya alarmante, de nuestro público. Bien merece, por ello, las alabanzas de los amantes de la buena literatura. Adelante, Don 
César, á ver si le hace las entrañas á ese público. Recojo la exhortación de El Lápiz para transferirla al presente y hacerla llegar a nuestra esforzada compiladora con fuerza y vitalidad renovadas, en este aquí y ahora de la República, no demasiado diferente del ya remoto tiempo de nacionalidad incipiente de Penson:

¡Adelante, Evelyn Marte Rodríguez, a ver si le hace las entrañas a ese público!

No debo terminar mi reseña -lo creo en verdad de justicia- sin dar las gracias al Instituto Tecnológico de Santo Domingo (INTEC) y al Fondo Editorial del INTEC por haber hecho realidad la publicación de la obra y por hacerlo con tanto cuidado,

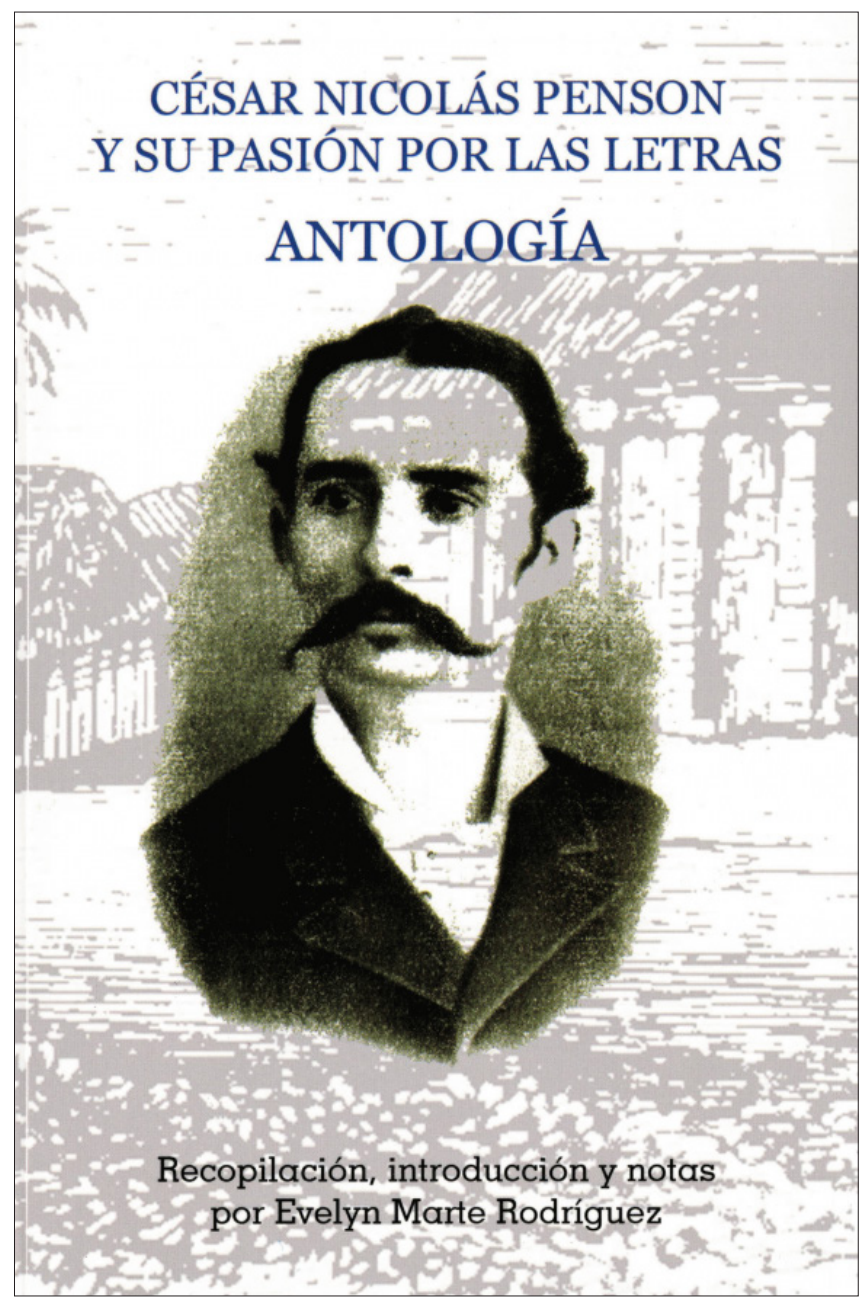

profesionalidad y esmero. Sé que el Fondo Editorial seguirá apoyando con determinación y entusiasmo la cultura y las letras nacionales, pues es su clara y decidida vocación y su razón de ser, al igual que la de todos los que hoy conformamos el INTEC, laboriosa colmena donde con tenacidad y esfuerzo se gestan día a día la ciencia y la cultura, tal como las abejas producen la cera y la miel.

\section{Referencias}

Marte Rodríguez, E. (2017). César Nicolás Penson y su pasión por las letras: antología. Santo Domingo: Instituto Tecnológico de Santo Domingo.

Rodríguez, C. P. (1974). Prólogo. En César Nicolás Penson, Cosas añejas: leyendas de Santo Domingo (Vol. XXXXV, págs. 1-12). Santo Domingo: Archivo General de la Nación.

Mañón Arredondo, M. de J. (1978). Prólogo. En César Nicolás Penson, Costumbres Antiguas y Modernas de Santo Domingo. Santo D omingo: Ediciones Fundación García Arévalo, pp. 9-10.

Rodríguez Demorizi. César Nicolás Penson (1882) Este texto de Demorizi aparece recogido en la Antología Evelyn Marte Rodríguez, p.p. 15-16. Y de ahí tomé la cita.

Rodríguez Demorizi, Emilio, El Telegrama, primer diario dominicano (7 de agosto de 1882), fragmentos de artículo publicado en periódico La Nación, Santo Domingo (7 de agosto de 1940, p. 7. Hemeroteca General de la Nación.

Penson, Gustavo (1940). Licenciado César Nicolás Penson (Rasgos biográficos), La Nación, Santo Domingo, 16, 19, agosto 1940 (s. p.). [La cita se recoge en la antología Marte Rodríguez, E. (2017). César Nicolás Penson y su pasión por las letras: antología. Santo Domingo: Instituto Tecnológico de Santo Domingo. 


\section{Datos de filiación}

Carlos Enrique Cabrera. Se licenció en Filología Hispánica en la Universidad Autónoma de Madrid (España) y realizó estudios de Bibliotecología y Documentación en instituciones educativas de esa capital europea. Ha publicado Reflexiones de bolsillo (2002); Tiempos difíciles (2010) y Conjuros y otros microcuentos (2013). Es además coautor del libro Español Universitario (Santillana Universitaria, 2006) y de la de información turística: Ciudad Colonial Santo Domingo (Tando Editora, 2011). 